\title{
Enunciación
}

\section{Iniciativa ciudadana “\#Noen3caínes". Análisis del discurso de un acontecimiento}

\author{
Citizens' initiative "\#Noen3caínes". Discourse analysis of an event \\ Luis Eduardo Ospina Raigosa ${ }^{1}$
}

Para citar este artículo: Ospina, L.E. (2016). Iniciativa ciudadana "\#Noen3caínes". Análisis del discurso de un acontecimiento. Enunciación, 21(2) 297-312.

Recibido: 28-abril-2016 / Aprobado: 11-octubre-2016

\section{Resumen}

En este artículo se realiza un estudio crítico del discurso (ECD) de un fragmento del video Narconovelas-Movimiento ciudadano \#Noen3caínes (García y Cartagena, 2013) que da cuenta de la iniciativa ciudadana \#Noen3caínes. En esta, los ciudadanos interpelan al medio de comunicación, lo que la constituye en una respuesta social. Como objetivo general se va a interpretar la respuesta social denominada Noen3caínes, a partir de los significados que se proponen en el video de análisis. Noen3Caínes tuvo efectos concretos en la pauta de la teleserie Tres Caínes del Canal RCN en Colombia. Al menos 13 marcas retiraron su publicidad gracias a la presión ciudadana desde internet, porque consideraron que su imagen no era afín con esa propuesta televisiva, asunto que no tiene precedente en la historia de los medios en Colombia.

Palabras clave: comunicación, discurso, movimientos ciudadanos, publicidad en televisión, redes sociales, teleserie.

\begin{abstract}
The article performs a Critical Study of the Discourse of a fragment of the video "NarconovelasMovimiento ciudadano \#noen3caines" (Garcia y Cartagena, 2013) which gives an account of the citizens' initiative Noen3caínes. In this initiative citizens question the media, and what it constitutes as a social response. The general objective is to interpret the social response called Noen3Caínes, from the meanings that are proposed in the video analysis. Noen3Caínes had concrete effects on the advertisement of the TV series of RCN in Colombia "Tres Caínes". At least 13 brands withdrew their advertising thanks to public pressure from the Internet because they considered that his image was not akin to that proposal on television, a matter which has no precedent in the history of the media in Colombia.
\end{abstract}

Keywords: citizen movements, communication, discourse, social media, TV series, TV advertising.

1 Candidato a Magíster en Comunicación y Medios. Universidad Nacional de Colombia. Correo electrónico: leospinar@unal.edu.co 


\section{INTRODUCCIÓN}

La teleserie Tres Caínes, emitida en Colombia por el canal privado de televisión $\mathrm{RCN}$, recibió críticas de diversos sectores sociales, por la manera como representó el accionar paramilitar en el conflicto armado. El programa mezclaba hechos reales con ficción y se basaba en la vida de los paramilitares Carlos Castaño, Vicente Castaño y Fidel Castaño. A modo de sinopsis, hay que indicar que inicia mostrando a los Castaño Gil como una familia de ganaderos que juran vengarse el día en que su padre es secuestrado y asesinado por la guerrilla de las FARC. A medida que transcurren los 80 episodios, arman y consolidan un ejército paramilitar. Este último es uno de los actores que ha contribuido a la grave situación de violencia que ha vivido Colombia. Han logrado imponerse, con el apoyo de sectores de la sociedad y del Estado (López, 2010), en zonas del país mediante amenazas, asesinatos, masacres, torturas y desplazamiento forzado (CNRR, 2013).

La producción televisiva Tres Caínes situó a los paramilitares como protagonistas y propuso una narración caracterizada, porque: marginaba la presencia de los sujetos victimizados (Valencia, 2013); llevaba al grado de ficción el accionar paramilitar como una venganza personal entre actores del conflicto, y desconocía la operación de apropiación ilegal del territorio (Zélik, 2015). Representó de forma estereotipada grupos sociales como los universitarios (Castaño, 2013) y utilizó la violencia constante como objeto recurrente en la trama, como otras tantas producciones televisivas en Colombia (véase Quiñones, 2009).

Esas posiciones que planteaba la teleserie levantaron críticas en varios sentidos. También generaron discusiones respecto a la manera como se cuentan hechos recientes de la historia colombiana. La teleserie se emitió entre el 4 de marzo y el 18 de junio de 2013. Durante ese tiempo, diversos grupos sociales se expresaron en contra. La Universidad de Antioquia (Consejo Académico, 2013), la Diócesis de Quibdó (2013) y Colombianos y
Colombianas por la Paz (Cuartas, 2013) emitieron comunicados cuestionándola. El Movimiento Nacional de Víctimas de Crímenes de Estado (Movice) realizó un plantón frente al Canal RCN (Tercer Canal, 2013). Además, medios de comunicación como Semana TV, Cablenoticias, Deutsche Welle y Canal Capital realizaron debates televisados sobre la teleserie. Por último, el periódico El Tiempo, la Universidad Externado de Colombia y la Autoridad Nacional de Televisión (ANTV), realizaron un foro abordando este fenómeno (ANTV, 2013).

Desde que inició la teleserie, surgió un movimiento en redes sociales abierto a cualquier usuario de internet, Ilamado "Noen3caínes". Los artífices de esta iniciativa utilizaron la etiqueta \#Noen3caínes en diversas redes digitales. La acción principal de este movimiento consistía en interpelar a las empresas que pautaban en aquella producción televisiva para que reflexionaran sobre sus valores de marca en relación con los contenidos presentados por esta. El procedimiento consistía en poner contenidos (fotos, frases, preguntas) en los perfiles y muros de las empresas anunciantes para que estas vieran que muchos de sus consumidores no estaban de acuerdo con el vínculo entre la marca y la teleserie.

El propósito de la iniciativa radicaba en comunicarles a las empresas anunciantes que contenidos violentos no representaban los valores que tales marcas decían tener. Esta campaña logró sintonizarse a un conjunto de participantes de 13.800 perfiles (solo en Facebook) (Naranjo, 2013) y desmontar un porcentaje importante de la pauta que tenía la teleserie. De acuerdo con datos de varios portales (Corporación Nuevo Arco Iris, 2013; Ayala, 2013; Radio Santafé, 2013; Siglo Data MMI, 2013; Ortiz, 2013), marcas como Nestlé, FalabeIla, Grupo Éxito, Carrefour, Nivea, Arroz Diana, GlaxoSmithKline (Dolex, Sensodine, Corega), Auteco, Ésika, Efecty, Winnie, entre otras, decidieron no seguir pautando en la teleserie.

El presente artículo tiene como propósito interpretar la respuesta social denominada \#Noen3caínes, mediante el análisis de un fragmento del 
video titulado Narconovelas-Movimiento ciudadano \#Noen3caínes (García y Cartagena, 2013). Este corpus de análisis es una entrada a los hechos que sucedieron como respuesta a la teleserie, lo cual permite responder al objetivo del estudio. El video objeto de análisis tiene relevancia analítica por las siguientes razones: a) es producido por los actores participantes, asunto que le da una relevancia social (López, 2001, p. 132); b) expresa su capacidad para utilizar los recursos semióticos y tecnológicos disponibles para la comunicación con otros (Kress, 2000); c) en la pesquisa realizada no se encontró otro material que recogiera cifras y explicara detalles de la iniciativa en redes sociales.

\section{LA RESPUESTA SOCIAL EN LOSESTUDIOS CRÍTICOS DEL DISCURSO}

Se partió de la categoría propuesta por Braga (2006), quien plantea que existen unos dispositivos de respuesta social que interpelan las producciones mediáticas. El mismo autor también se propone investigar las maneras colectivas y organizadas que tienen las sociedades para interpelar la acción de los medios de comunicación. Pensar en ello es detenerse sobre múltiples mecanismos sociales para actuar sobre los medios de comunicación. Son "todos os procesos organizados da sociedade sobre a mídia e seus productos, e os modos como estes se articulam com a produção e a recepção eventualmente tensionando-as" (Braga, 2006, p. 33) ["Son todos los procesos organizados de la sociedad sobre sus medios de comunicación y sus producciones y los modos como estos se articulan con la producción y la recepción y sus posibles tensiones"] (traducción propia).

El concepto de respuesta social se utiliza exclusivamente para dar cuenta de la tensión entre medios de comunicación y grupos sociales. Esto quiere decir que está dirigida hacia los productos y los discursos de los medios de comunicación y no de otras instituciones sociales que pueden ejercer dominación desde el discurso (Estado, escuela, Iglesia). La potencia del concepto de respuesta social reside en su dimensión de ser discurso contestatario frente a los medios de comunicación.

El discurso se constituye como un elemento importante de la respuesta social. Por tal motivo se entiende la respuesta social como un conjunto de acciones complejas que tienen un alcance discursivo. El discurso es un fenómeno práctico, social y cultural, donde los usuarios del lenguaje realizan actos sociales y participan en la integración social enmarcada en contextos sociales y culturales (Van Dijk, 2001, p. 21). Todos los actos comunicativos son del orden de la interacción entre actores. Según Van Dijk (2001), "la actividad discursiva se vuelve socialmente real si tiene consecuencias sociales reales" (p. 30).

La respuesta social se ubica, entonces, como una acción discursiva, no solo por su capacidad de interpelar a los medios de comunicación desde una forma de protesta -mediante una campaña web-, sino por desplegar las capacidades de expresión de un grupo social y emitir un contenido audiovisual a través de la plataforma YouTube. En este artículo, el discurso se entiende como conocimientos construidos socialmente que permiten dar cuenta de la realidad. De acuerdo con Pardo Abril (2012), los discursos se inscriben en formas materiales concretas mediante las cuales circulan. "Así, el discurso desarrolla su potencial de comunicación en toda la comunidad" (p. 23).

El enfoque intelectual de los estudios críticos del discurso (ECD) $)^{2}$ propone un conjunto de referencias para comprender la realidad desde el desarrollo del concepto de discurso. Los estudios en este campo parten de que la realidad social y cultural tiene una faceta discursiva que le da significado. Este consenso ha permitido centrar el interés en el discurso como generador y transformador de la realidad.

Los ECD son un enfoque interdisciplinar que surge de las Ciencias Sociales y Humanas. Apropió

2 A partir de 2010, los diferentes enfoques académicos que compartían el campo de los estudios del discurso desde una perspectiva crítica (ACD), se empezaron a denominar estudios críticos del discurso (ECD). 
elementos de varias disciplinas para constituirse como una herramienta epistémica que interprete los problemas sociales y culturales. "Mediante la apropiación de diferentes metodologías de investigación y de distintos posicionamientos teóricos, los estudios del discurso han posicionado los principios de la complejidad, la diversidad y el diálogo, como criterios de validación del conocimiento científico" (Pardo, 2011, p. 44). Un consenso de los ECD plantea que las prácticas de comunicación producen universos simbólicos que inciden en la comprensión de la realidad social. Así, la comunicación, los medios masivos, las relaciones de poder, etc., son procesos correlacionados con el discurso donde se expresan deseos, intereses y estrategias de los grupos sociales que entran en interacción.

\section{La estrategia de legitimación}

La legitimación es una de las estrategias discursivas que resultan más afines a los discursos de respuesta social. Por provenir de grupos sociales que han sufrido procesos de exclusión simbólica, esta forma de legitimación sirve al propósito de expresar la concepción de mundo de los discursos que han sido in-visibilizados. En el caso de la respuesta social, el discurso propuesto impide cimentar formas de pensamiento de los grupos dominantes. Esta investigación pretende reconocer y dimensionar estos discursos, pues según Berger y Luckmann (2003):

Cuando grupos que habitan los universos poseen versiones diferentes o divergentes del mismo, estas versiones y grupos quedan estereotipadas o marginadas al estar al margen de las realidades impuestas o establecidas de las cuales subyacían. Este tipo de versiones se convierten en alternativas de esos sistemas universales compartidos (p. 131).

La legitimación es el acto de conceder aceptabilidad a los actores sociales dentro de un orden específico, en este sentido la respuesta social propone una línea de pensamiento que va en contra de los significados imperantes. La iniciativa ciudadana les plantea unos interrogantes a sectores de la sociedad y propicia una reflexión en torno a la representación del conflicto armado en televisión.

\section{Un acontecimiento generado desde la Web}

La iniciativa \#Noen3caínes se entiende como una respuesta social en la red, que no se limita al cerco de polaridades al que se reducen varios grupos y sectores sociales al hablar del conflicto armado colombiano (el tema de la teleserie), sino que anuncia, en acuerdo con Lazzarato (2006), que algo ha sido creado en el orden de lo posible, es decir, un acontecimiento que no comporta una solución al problema, sino la apertura de posibles; expresa nuevas posibilidades de interpelación y de comprensión, nuevas posibilidades de ser y de vivenciar.

En los movimientos sociales actuales, las lógicas de agrupación se ven transformadas. Lazzarato (2003, 2006, 2007) asegura que las nuevas agrupaciones sociales se relacionan por afectos y afinidades, así como por relaciones cooperativas. "Pequeñas y grandes invenciones de nuevos mecanismos de hacer y decir la política, practicados por una multiplicidad de sujetos, más o menos anónimos, en mutación" (Lazzarato, 2006, p. 45). El concepto de acontecimiento se refiere a la acción política de una multiplicidad de subjetividades en mutación. En \#Noen3caínes, el acontecimiento se generó por la generación de prácticas colectivas en la web.

\section{METODOLOGÍA}

Este estudio es de corte cualitativo. El interés por comprender $-y$ no solamente describir o cuantificar el fenómeno- mediante un proceso de interpretación denota este carácter. Por efectos de espacio, analiza dos fragmentos (0:12-0:41) (2:393:26), del video Narconovelas-Movimiento ciudadano \#Noen3caínes (García y Cartagena, 2013) disponible en YouTube (https://www.youtube.com/ watch?v=YAFW9qDxJlc). 
Las Ciencias Sociales y Humanas aportan una base conceptual para comprender el fenómeno estudiado. La posición epistemológica se enfoca desde el paradigma interpretativo, con un acento en la necesidad de comprender el significado de las acciones sociales en el mundo de la vida desde la perspectiva de sus participantes. En este paradigma, "el lenguaje es entendido como un recurso y como una creación, es una forma de reproducción y producción del mundo social" (Vasilachis de Gialdino, 1992, p. 153.

Se apoya en la hermenéutica para la captación y reconstrucción del significado mediante técnicas interpretativas que permiten describir, descifrar, analizar e interpretar el significado del discurso estudiado. "La hermenéutica puede comprenderse como un método para aprehender y producir relaciones significativas" (Meyer, 2003, p. 38).

El acento crítico se expresa al investigar un caso donde se lleva a cabo la reproducción y el abuso de poder desde el discurso mediático, y además se hace énfasis en las posibilidades de respuesta que asumen quienes son despojados de recursos simbólicos y materiales. En otras palabras, se dimensiona una iniciativa ciudadana, donde un grupo social responde frente a un contenido mediático: la producción televisiva Tres Caínes.

Este ECD busca descifrar los recursos discursivos que el corpus tiene como expresión del fenómeno estudiado. Estos recursos permiten entender las maneras en que los agentes apropian objetos simbólicos para la construcción de significado. Los recursos muestran "el conjunto de elementos sígnicos interrelacionados que son desplegados en los procesos de producción y comprensión discursiva" (Pardo, 2012, p. 120)

Luego de descifrar los recursos se determinan las estrategias discursivas utilizadas en el corpus y en un proceso inferencial se relacionan con el marco sociohistórico. El proceso inferencial se hace para trascender la dinámica comunicativa del corpus y generar niveles de comprensión sobre las prácticas sociales que constituyeron el fenómeno estudiado.

La técnica aplicada es estadístico-descriptiva articulada al análisis multivariado; se focaliza en la descripción de los recursos. Esta técnica se ejecutó con ayuda del programa NVivo que permite al investigador describir los temas más recurrentes en los enunciados del corpus, a través de determinar las frecuencias y recurrencias lingüísticas en ellos.

El procedimiento se realiza en tres momentos que van desde la descripción del corpus, hasta el análisis y la interpretación. En ese tránsito se pone en relación las unidades discursivas principales, los recursos discursivos que utilizan y mediante inferencias se propone una manera de entender los alcances políticos y sociales de esas expresiones discursivas.

Los tres momentos son: a) descripción del video objeto de análisis: en este momento se da cuenta de las partes en que se estructura el video, y se describen los elementos gráficos y verbales presentes en el corpus. b) Reconocimiento del tejido semiótico: inicia reconociendo las voces discursivas. "Esta categoría permite identificar el papel del actor social en la construcción y comprensión discursiva, sus roles, sus puntos de vista, la coherencia discursiva y el conjunto de recursos que apropia para expresarse" (Pardo, 2012, p. 121). c) Del discurso a las estructuras socioculturales: en este tercer momento se pretende generar explicaciones que trasciendan la dinámica comunicativa del corpus y su materialidad, para dar cuenta de un conjunto de relaciones que se establecen entre lo que se propone discursivamente y las realidades culturales y políticas en las que inciden los discursos. El discurso se entiende como acto de comunicación intersubjetivo que tiene implicaciones sobre la realidad sociocultural. La interpretación de estas consecuencias se realiza mediante las inferencias entre las unidades discursivas y su contextualización sociohistórica. 


\section{ANÁLISIS DEL VIDEO “NARCONOVELAS- MOVIMIENTO \#NOEN3CAÍNES" CIUDADANO}

El video es publicado 12 de junio de 2013, por el usuario de YouTube Camilo García. En los créditos finales aparecen como realizadores Camilo García y Ana Cartagena que son participantes de la iniciativa ciudadana, pero no fueron los artífices de esta. El video se divide en dos grandes partes: la primera, la constituye una animación que utiliza recursos gráficos como fotografías, frases, enunciados y piezas publicitarias de la iniciativa; la segunda, la constituyen dos voces: la de Federico García, profesor de la Universidad Javeriana, que da su punto de vista sobre los problemas de orden histórico y narrativo que tiene la teleserie Tres Caínes, la otra voz, la de Daniel Naranjo, uno de los artífices de la iniciativa. Sobre esta voz se concentrará el análisis, pues explica y justifica la manera en que operó \#Noen3caínes y permite comprender las lógicas del movimiento ciudadano desde uno de sus creadores.

El video inicia con una animación donde se ve un televisor de perilla en el centro del plano y dos sillones dispuestos a uno y otro lado del televisor. Luego de realizar un zoom sobre la pantaIla del televisor, donde se presentan una plantilla prediseñada que utiliza un recurso gráfico para ir enunciando, paso a paso, una serie de frases que explican cómo fue la trayectoria del movimiento ciudadano:

$\rightarrow$ Boicot. Movimiento cívico hace un llamado a la coherencia de imagen de marca

$\rightarrow$ Los 3 caínes

$\rightarrow$ Reacción en las redes sociales

$\rightarrow$ Nace movimiento cívico

$\rightarrow$ Boicot pauta publicitaria

$\rightarrow$ Reacción de los anunciantes

$\rightarrow$ Gran impacto en la comunicación pública

$\rightarrow$ ¿Existen otras posibilidades para contar esta clase de historias? [Intervalo temporal: 0:12-0:41]. (García y Cartagena, 2013).
Para efectos de este análisis interesa profundizar en el primer enunciado que engloba elementos generales de lo que fue la iniciativa y se relaciona directamente con la voz de Daniel Naranjo, uno de los artífices de la respuesta social. Los creadores del video utilizan el término boicot para denominar esta iniciativa. Un boicot consiste en negarse a realizar una relación comercial de compra o de venta con un individuo o empresa que es considerado -por los participantes del boicot- como ejecutor de algo moralmente reprobable. El boicot es considerado una táctica de consumo ético. De acuerdo con Monroe Friedman (citado por De Miguel Beriain, 2013), el boicot es un "intento de una o más partes de obtener ciertos objetivos urgiendo a los consumidores individuales a evitar que compren algunos artículos en el mercado" (p. 29).

Aunque los iniciadores de la campaña (Daniel Naranjo, Andrés Ochoa, Juan Felipe Builes y Marcela Trujillo) no hayan denominado la iniciativa como boicot, los autores del video (Camilo García y Ana Cartagena) apropiaron este término para nombrar el movimiento. Cabe resaltar un elemento de la respuesta social en la web, que consiste en la participación de actores que se apropian de la causa y que utilizan sus capacidades expresivas (realizar el video y denominar el movimiento boicot) para contribuir al propósito de la iniciativa. El video en su conjunto y la unidad léxica boicot en particular son una lectura hecha por los usuarios que se sumaron a la iniciativa lo que muestra unos participantes que se apropian de la respuesta social y le dan su propio significado y expresión.

Usar el concepto boicot para referirse a la acción implica posicionar de forma diferente a los actores que participan en ella. Ya no son consumidores pasivos sino que son actores con la capacidad de boicotear un producto televisivo. El boicot es una acción de carácter colectivo, lo que implica que ya no hay actores atomizados sino agrupados actuando en conjunto por una causa común bajo referentes éticos, sobre todo porque el boicot se propone como una táctica de consumo de este carácter. 
En términos socioculturales, la práctica de generar contenidos (como el video) y de denominar la respuesta social de cierta manera (boicot), expresa formas de vinculación en la Web que están en torno a valores de orden cultural y de modos de vida, desligándose de los intereses sectoriales. "En oposición a modos de organización y comunicación verticales, burocráticos y rígidos, de ahí que se privilegie la adopción de un tejido organizacional y comunicativo en red" (Rueda, 2008, p. 14). El hecho de que todos los que apoyan la iniciativa se vinculen de la misma manera (como activistas) rompe con las lógicas jerárquicas y establece unas prácticas de participación que los propone como generadores de nuevos contenidos y como enunciadores de lo que significa el movimiento.

A partir del minuto 2:38 el video incorpora un registro audiovisual externo que fue grabado en el foro "La responsabilidad de los medios de comunicación frente a la memoria histórica y las víctimas del conflicto". Específicamente un fragmento del panel "Medios y redes sociales, dos puntos de vista" (ANTV, 2013). Este foro fue organizado por la ANTV, la Casa Editorial El Tiempo y la Universidad Externado de Colombia 3 .
En la figura 1 se relaciona la imagen de Daniel Naranjo, con la transcripción de lo que va enunciando en el video objeto de análisis. Cabe indicar que los creadores del video objeto de análisis editaron la intervención en el foro. Por ello, al rodar el video entre el minuto 2:38 y 3:51 se ven unos leves saltos que permiten determinar dónde ha sido editado. En YouTube se puede acceder al contenido del panel completo (ANTV, 2013).

En el momento de la realización del foro, algunos anunciantes ya habían retirado su pauta publicitaria de la teleserie por sugerencia de la iniciativa ciudadana \#Noen3caínes. Ante estos hechos, el moderador del foro y Tulio Ángel, representante de Asomedios, plantean si esa acción se considera un acto de censura.

La voz de Daniel Naranjo responde a la acusación de censura mediante el uso de diversos recursos como la argumentación y la autorización y algunas figuras retóricas como la metonimia y la antítesis. En ese testimonio se construye una estrategia de legitimación para defender la validez de la iniciativa \#Noen3caínes. En la figura 1 se aprecia la transcripción, con un fotograma del momento en que enuncia su voz.

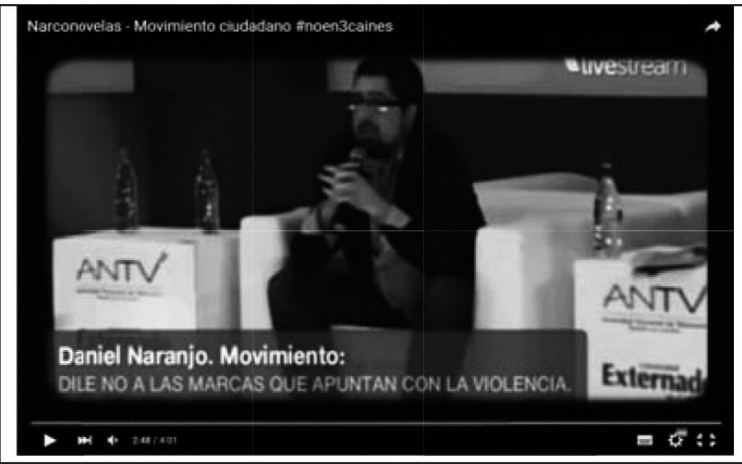

[El argumento de la censura es un argumento que] honestamente siempre, a los organizadores del movimiento o de esta iniciativa ciudadana, nos ha parecido un argumento traído de los cabellos. ¿En qué sentido? Nosotros no estamos censurando el hecho de que ese contenido exista o no. Estamos haciendo un llamado y el llamado es simple: 'Si tú eres el dueño de esa marca, ¿te gustaría pautar allí?"”.

Figura 1. Daniel Naranjo A. Video Narconovelas-Movimiento ciudadano \#Noen3caínes

Fuente: García y Cartagena (2013; intervalo temporal: 2:38-3:02).

3 Es necesario mencionar algunos aspectos del panel "Medios y redes sociales, dos puntos de vista" para contextualizar el escenario donde se enunció el testimonio de Daniel Naranjo que se incorpora al video analizado. El panel propone dos discursos opuestos respecto al papel que desempeñan las redes sociales como punto de encuentro para organizar ciudadanos frente a los contenidos que les ofrece la televisión. Es conducido por un moderador que propone algunas preguntas para que sean abordadas por los dos actores en el debate: Túlio Ángel (Asomedios) y Daniel Naranjo (\#Noen3caínes). 
En el enunciado inicial "[El argumento de la censura es un argumento que] honestamente siempre, a los organizadores del movimiento o de esta iniciativa ciudadana, nos ha parecido un argumento traído de los cabellos" (García y Cartagena, 2013; intervalo temporal: 2:38-2:47), la voz de Naranjo hace una atribución a la unidad "argumento de la censura" indicando que le parece "traído de los cabellos". Esta atribución resulta muy importante a efectos de no equiparar la respuesta social de la iniciativa ciudadana con la censura y tematizar sus propios puntos de vista.

La metonimia "argumento traído de los cabellos" se propone mostrar que el concepto al que se hace referencia (censura) no se ajusta a la realidad de lo sucedido. En otras palabras, es una idea "descabellada". La metonimia es una figura retórica que utiliza una entidad para referirse a otra (Lakoff y Jonhson, 2004, p. 74). En este caso, es una metonimia de la parte por el todo, "la parte del todo que escogemos determina en qué aspecto del todo nos centramos" (p. 74).

De acuerdo con Pardo (p. 176) las metonimias son uno de los elementos lingüísticos ejecutados para llevar a cabo la estrategia de legitimación en el discurso. Si la parte de la metonimia son los cabellos, el todo lo constituye la cabeza, entendiendo que la cabeza se asocia con los procesos intelectivos. Así, se indica que el concepto al que se refiere (la censura) está por fuera de la cabeza, es decir que no tiene un carácter racional. La censura entonces es traída de fuera del pensamiento, externo a la cabeza, ubicado en un lugar (los cabellos) donde no existe ningún proceso intelectivo.

En un sentido amplio, censurar consiste en intervenir de forma directa la pieza comunicativa para transformarla o impedir que circule. Para García Morales (2013) hay un concepto clásico de censura definido como: "[...] cualquier medida limitativa de elaboración o difusión de una obra que consista en el sometimiento a un previo examen por un poder público y cuya finalidad sea enjuiciar la obra con arreglo a unos valores abstractos y restrictivos de la libertad" (p. 246). En el escenario sociopolítico, la censura es un acto jurídico administrativo del que solo hacen uso actores ampliamente legitimados con facultades de justicia. Cuando se ejecuta desde el Estado, se hace mediante comisiones de control o consejo de expertos y sobre la base del poder estatal para proteger el bienestar de los ciudadanos.

Bajo estos parámetros, el concepto de censura queda sin soporte, toda vez que no se ha intervenido, en forma o contenido, la teleserie Tres Caínes. Las características para el ejercicio de censura están bastante restringidas y se delegan exclusivamente a las instituciones de poder. Los grupos sociales que respondieron frente a la teleserie no poseen las facultades, las herramientas y la legitimidad para ejercer un acto de censura, por tanto es un concepto que no permite comprender lo que significó el fenómeno de la respuesta social frente a la teleserie en cuestión.

Luego de la metonimia, la voz testimonial orienta los significados para realizar una precisión de lo que significa la iniciativa ciudadana. Inicia usando una estrategia interrogativa que da paso al recurso de la argumentación "¿En qué sentido? Nosotros no estamos censurando el hecho de que ese contenido exista o no. Estamos haciendo un Ilamado, y el Ilamado es simple: 'Si tú eres el dueño de esa marca, ¿te gustaría pautar allí?'" (García y Cartagena, 2013; intervalo temporal: 2:48-3:01). Con ello se aclara que no se está impidiendo la circulación de un contenido, sino que se está llamando a la coherencia de marca.

Para consolidar la estrategia de legitimación, la voz de Naranjo apropia el recurso de la argumentación y el uso de figuras retóricas para construirlo. Inicia con la palabra "Nosotros", que es el pronombre en primera persona del plural, y que evoca la presencia de multitudes y refuerza el carácter plural de la acción de respuesta social. Se expresa la enunciación de una multitud.

La frase "Nosotros no estamos censurando el hecho de que ese contenido exista o no. Estamos haciendo un llamado, y el Ilamado es simple: 'Si tú eres el dueño de esa marca, ¿te gustaría pautar 
allí?'" (García y Cartagena, 2013; intervalo temporal: 2:48-3:01), presenta un argumento de definición a partir de la figura retórica de la antítesis. En este caso se define lo que no es el movimiento ciudadano \#Noen3caínes ("No estamos censuran-

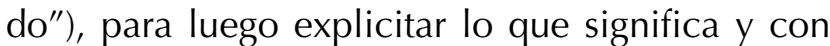
ello cumplir su propósito de legitimación.

La antítesis es una figura retórica que consiste en contraponer dos expresiones que expresan ideas de significado opuesto (Mortara, 1991). Aquí se contrapone "censura" con "llamado". En este sentido, la voz desarrolla una cadena de argumentos por contraste. El argumento se distancia de un concepto (censura) y parte de ese contraste para definirse. Se utiliza una reiteración ("Estamos haciendo un Ilamado y el Ilamado es simple") para focalizar sobre la unidad léxica "llamado", que define la acción discursiva fundamental del movimiento ciudadano: "Ilamado a las marcas".
Esta forma de tematizar indica que, desde la voz de Daniel Naranjo, se le está dando prioridad a ciertos temas en detrimento de otros. Como se puede apreciar en la figura 2 (producida por $\mathrm{NVivo}^{4}$ ), el término censura no aparece, por el contrario se hace referencia a la acción principal de la iniciativa ciudadana "un Ilamado" y al actor que se convocó a ese llamado (las marcas). Esta forma de tematizar prioriza los intereses principales del discurso de Naranjo y anuncia las unidades léxicas desde donde se va a construir la estrategia de legitimación.

La figura 2 es el resultado del análisis estadístico textual que se realizó con el programa NVivo al corpus. A la izquierda se ilustran las palabras que tienen mayor frecuencia en el discurso de Naranjo. A la derecha se muestra la correlación de la palabra "coherencia" con las oraciones que están antes y después en dos momentos del discurso.

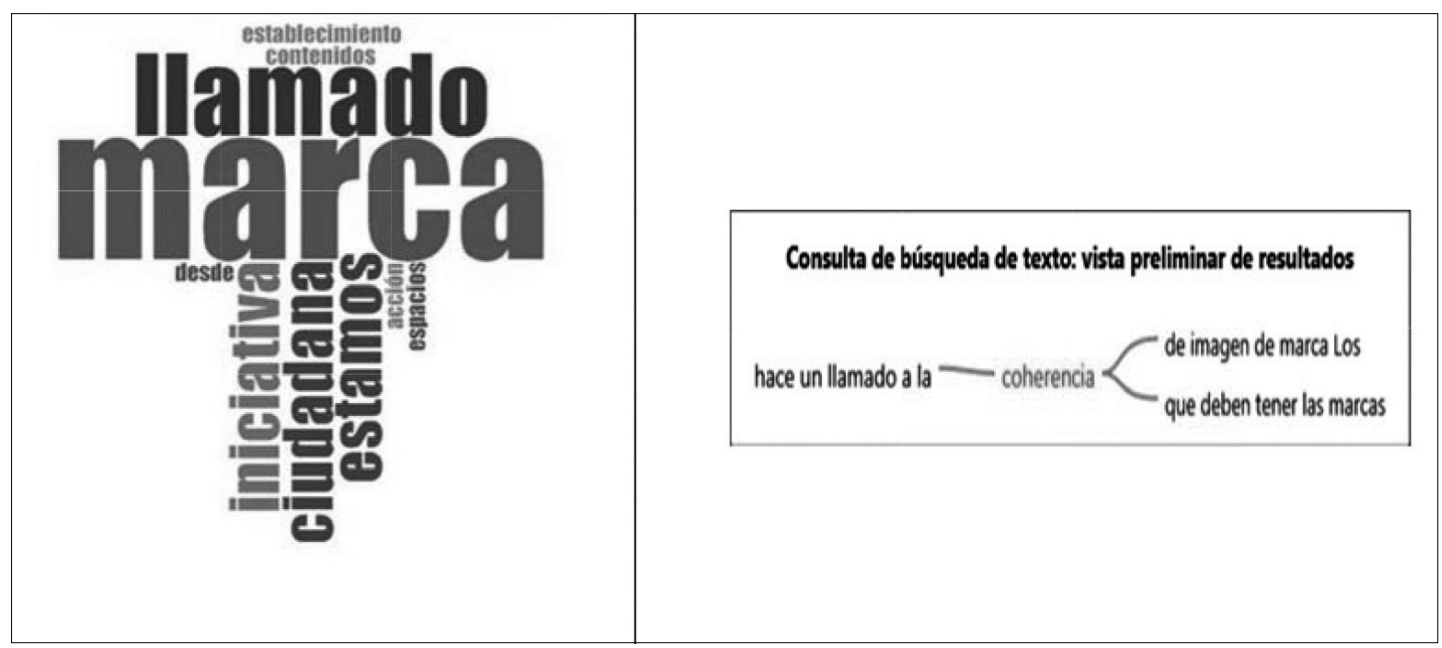

Figura 2. Palabras más frecuentes/correlación de la palabra "coherencia" en el corpus.

Fuente: producido por NVivo.

4 Nvivo es un programa que ayuda a organizar, describir y encontrar perspectivas en datos no estructurados. Sus aplicaciones principales hacen posible la marcación del corpus para facilitar el análisis y crear nodos que permiten relacionar las distintas unidades de análisis. También se puede segmentar en la línea del tiempo los videos y audios para su interpretación detallada. Más información en: http://www.qsrinternational.com/nvivo-spanish 
Hacer un Ilamado a la coherencia de marca es intervenir en una situación sociopolítica convocando a unos actores (los anunciantes) y designando a otros para enfrentarlos (el Canal RCN). En este caso las empresas anunciantes tienen una filiación con los ciudadanos/consumidores que interpelan. Esta relación es dada por los mecanismos de consumo. Hacer un llamado a que un actor social como las empresas anunciantes sean coherentes configura un nuevo espacio sociopolítico convocando a otros actores en el circuito comunicacional de la televisión en el que tradicionalmente se engloban canales de televisión y ciudadanos. Cuando Naranjo pregunta "si tú eres el dueño de esa marca, ¿te gustaría pautar allí?" (García y Cartagena, 2013) está interpelando a un interlocutor diferente y lo está convocando a tomar una posición.

Las implicaciones políticas de este acto fueron contundentes en el sentido que 13 marcas tomaron una decisión en favor de la iniciativa y retiraron sus anuncios de la teleserie Tres Caínes. De este análisis se permite inferir que el acto de interpelar a los anunciantes y la acción de retiro por gran parte de ellos indica que los medios de comunicación son actores articulados a un circuito de producción. Obligar a tomar una postura coherente a otro de los actores de ese circuito (los anunciantes) desestabiliza las lógicas de acción de los medios de comunicación.
En la figura 3 se observa la continuación de la voz testimonial. En este caso realiza un desarrollo al modo de proceder de la iniciativa ciudadana y continúa con la argumentación por contraste frente a la acusación de la censura.

Los argumentos por contraste se convierten en una manera de proponer el discurso. En el discurso se representan dos polos de la situación donde uno de ellos se propone como negativo (la censura) y el otro como positivo (Ilamado a la coherencia de marca). Se deriva un interés por explicitar, cada vez con más elementos positivos, la acción del movimiento cívico y con ello alcanzar legitimidad entre los interlocutores. En el fragmento:

No estamos diciendo: “¡Retiren la pauta!". Porque es que eso no es lo que... No, no, no, no, stop. El Ilamado es este: "Si tú fueras el dueño de esa marca, si tú eres el encargado de esa marca, si tú has trabajado durante años por tratar de construir una imagen de marca... (García y Cartagena, 2013; intervalo temporal: 3:03-3:19).

Se continúa con la estrategia de legitimación. En este caso, la voz de Naranjo formula una expresión contrastiva con la frase "No estamos diciendo: ' $R e-$ tiren la pauta!'. Porque es que eso no es lo que...'. No, no, no, no, stop". Inicia con una exageración (que se marca además porque sube el tono de su voz) donde propone expresar que el Ilamado a la

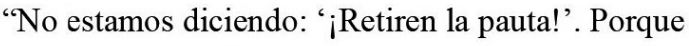
es que eso no es lo que... No, no, no, no, stop. El llamado es este: 'Si tú fueras el dueño de esa marca, si tú eres el encargado de esa marca, si tú has trabajado durante años por tratar de construir una imagen de marca, ¿tendrías que estar ahí?’ Eso es todo.

Nuestro único pedido ha sido que se plantee desde el respeto".
}

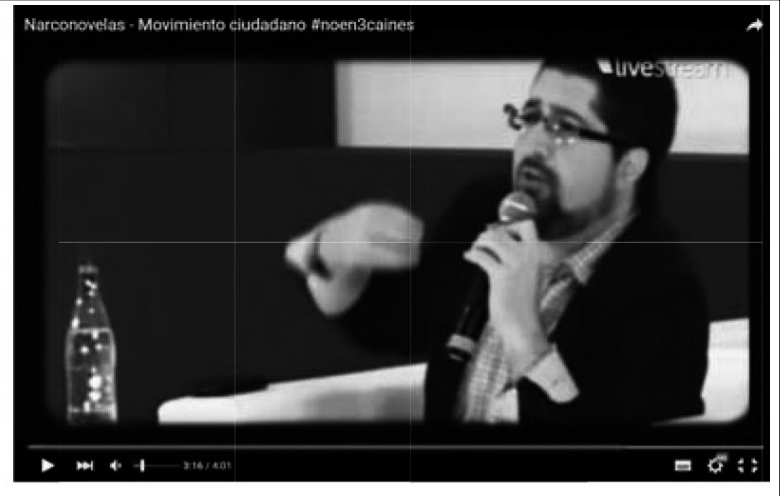

Figura 3. Daniel Naranjo B. Video Narconovelas - Movimiento ciudadano \#Noen3caínes

Fuente: García y Cartagena (2013; intervalo temporal: 3:03-3:26). 
coherencia no es un acto de exigencia. La exclamación usada sirve al propósito de exagerar la voz para simular lo que significa una exigencia. Por ello, a renglón seguido, usa una reiteración ("no, no, no stop") para indicar que no existe tal exigencia, que la iniciativa \#Noen3caínes opera de otra manera diferente a exigir.

Lo que se construye con este contraste (primero exagerando y luego reiterando la negación) es un proceso de persuasión apelando al valor de la coherencia que deberían tener las marcas y la posibilidad de llamado del que pueden hacer uso los ciudadanos. La legitimación se constituye como una forma de aprobación moral en la realización de acciones por parte de un grupo social (Martín Rojo y Van Dijk, 1998). Como se ha mostrado la argumentación por contraste permite distanciarse de una acción moralmente reprochable (la censura) y desarrollar un argumento de definición articulado a un valor aceptado: la coherencia.

Esta cadena de argumentos por contraste y el uso de figuras retóricas como la metonimia, la exageración y la reiteración sirven al propósito de referenciar que las acciones del movimiento ciudadano \#Noen3caínes se ajustan al orden sociopolítico, que están dentro del sistema legal y que obedecen a orientaciones de orden moral. En este sentido el discurso construye una estrategia de legitimación.

Según L. Martín Rojo y T. van Dijk (1998), "la legitimación es más necesaria en el contexto de las acciones controvertidas, las acusaciones, dudas, crítica o conflictos sobre las relaciones entre grupos, dominación y liderazgo" (p. 10). La serie de acciones que emergieron en este fenómeno -la respuesta social de un movimiento ciudadano, la toma de decisión de los anunciantes, otras respuestas sociales como el plantón y los comunicados- dejaron ver nuevas posibilidades de acción de respuesta contra los medios, aspecto que altera la relación de dominación discursiva que los grandes medios de comunicación ejecutan a amplios sectores de la población colombiana. Esta alteración se configura como un fenómeno controvertido donde se enuncian discursos en busca de legitimidad.
El discurso legitimador que apropió el testimonio de Daniel Naranjo se organiza mediante el contraste y la explicación de las acciones del movimiento \#Noen3caínes. Este discurso desemboca en una conclusión de tipo ético: es legítimo que los ciudadanos pidan coherencia a los anunciantes por el lugar donde pautan. Se procura una aceptabilidad social, moral y política del movimiento ciudadano desde el discurso.

Esta estrategia de legitimación discursiva se ejecutó cuando muchos anunciantes se habían retirado, en este sentido se convierte en una respuesta a las críticas explícitas que la denominaban como censura. La argumentación por contraste sirve al propósito de expresar que la iniciativa ciudadana \#Noen3caínes es una acción válida. Esta función sociocognitiva fortalece el conjunto de participantes de la iniciativa y legitima ese colectivo frente a grupos externos.

Daniel Naranjo tiene un rol de ciudadano (televidente/consumidor), pero además es uno de los creadores de la iniciativa. Esta faceta de artífice hace que sea un hablante legítimo para hablar de la iniciativa ciudadana \#Noen3caínes. Los argumentos por contraste que enuncia Naranjo sirven al propósito de exponer las acciones del movimiento como causas fiables. Para Martín-Rojo y Van Dijk (1998) hay tres condiciones que caracterizan los discursos legitimados:

Los discursos se consideran legitimados cuando se cumplen las tres condiciones siguientes: (i) la fuente del discurso (el hablante, la institución a la que representa, etc.) tiene que estar legitimada; (ii) la representación de los acontecimientos que se realiza a través del discurso debe considerarse verídica y fiable; (iii) tanto las formas lingüísticas (registros, dialectos, etc.) como discursivas (géneros, estrategias discursivas) deben considerarse socialmente apropiadas, autorizadas o "políticamente correctas" (p. 45).

La voz de Naranjo -y de los partícipes de la iniciativa-, se caracterizó por enunciarse desde un lenguaje formal y sin expresiones de exigencia o de violencia. Cuando Naranjo expresa: "Nuestro único pedido ha sido que se plantee desde el respeto" (García y Cartagena, 2013; intervalo temporal: 3:22-3:26) 
(figura 3), se está indicando que el colectivo actúa de manera respetuosa frente a los otros actores sociales y de una manera "políticamente correcta". Con ello, el discurso de la iniciativa ciudadana \#Noen3caínes cumple con las tres condiciones para convertirse en un discurso legitimado.

La pregunta "¿tendrías que estar ahí?", dirigida hacia las empresas anunciantes fue la ruta escogida del movimiento ciudadano \#Noen3caínes. En principio es una apuesta a lo impredecible. Sus alcances y resultados no están predeterminados, por ello es un ejemplo expedito de lo que significa un acontecimiento. El acento de la campaña web, con todas sus capacidades expresivas y los rasgos de horizontalidad y participación de los que se hablaron páginas atrás, son evidencia de que este discurso de respuesta social se originó abierto al devenir de los acontecimientos, puesto que convocó a interlocutores de muchos órdenes que se adhirieron de forma activa y libre.

La respuesta social de los usuarios que se vincularon a la campaña, así como de las 13 marcas que dejaron de pautar en la teleserie demuestra la capacidad de este discurso. Todo discurso de respuesta social interpela a varios actores sociales y genera ecos en los interlocutores apelados. "Implica una comprensión, una respuesta-reacción, una capacidad de respuesta activa, una toma de posición, un punto de vista, una evaluación de respuesta y la suscita más allá de lo que su mismo autor pudiera desear" (Lazzarato, 2007, p. 38).

De acuerdo con el análisis, la acción discursiva que recoge la esencia del movimiento \#Noen3caínes es "hacer un Ilamado a la coherencia de marca". Cuando se le asigna un carácter creativo a la acción discursiva "hacer un Ilamado" se está reconociendo su potencial de transformación del mundo. Se le está comprendiendo como un acontecimiento que abre un orden de posibilidades de ser y de existir (Lazzarato, 2007). Esta acción discursiva presenta nuevas rutas de acción para que grupos sociales expresen sus desacuerdos frente a los contenidos mediáticos que circulan en la televisión colombiana. "El acontecimiento da a ver lo que una época tiene de intolerable, pero también hace emerger nuevas posibilidades de vida" (Lazzarato, 2006, p. 36).

El hecho de que 13 marcas se retiraran de la teleserie da cuenta de que esta respuesta social movilizada desde la web alcanzó resultados concretos. En la figura 4 se pueden leer dos comunicados de retiro de parte de los anunciantes.

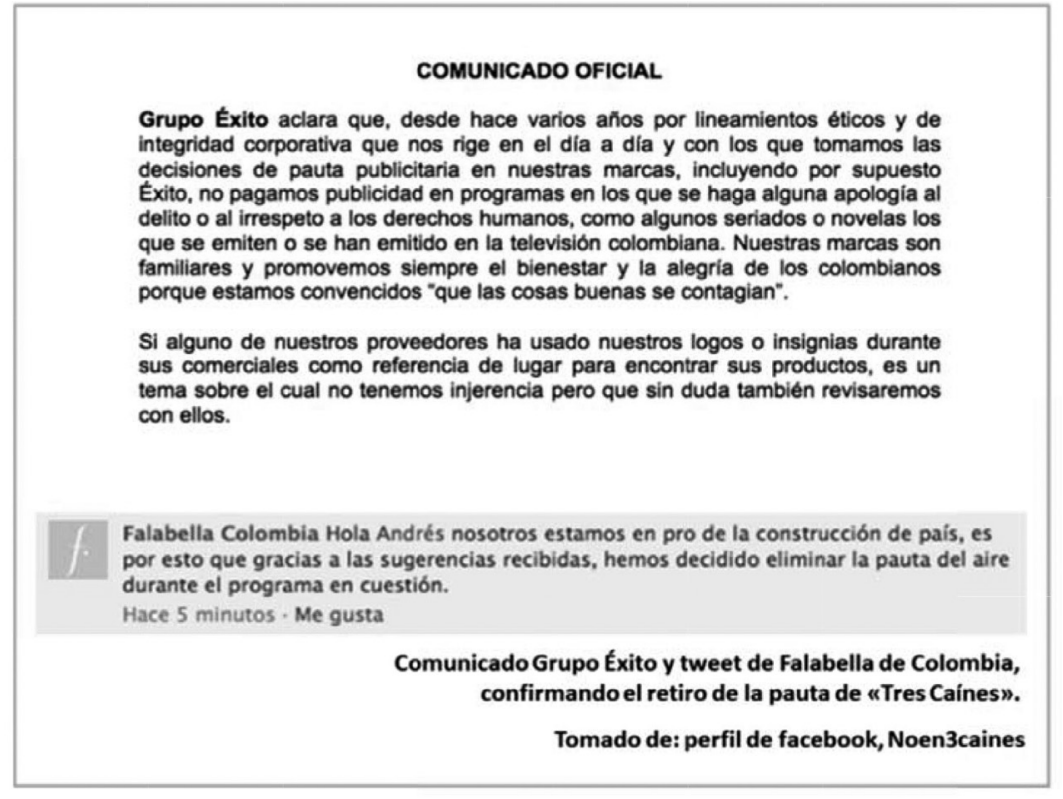

Figura 4. Retiro de anunciantes

Fuente: perfil de Facebook, \#Noen3caínes (https://es-es.facebook.com/Noen3caines-490599870999308/) 


\section{CONCLUSIONES Y DISCUSIÓN}

Analizar el discurso de las respuestas sociales permite entender el acontecimiento desde su dimensión discursiva. En este fenómeno, el discurso es el componente central que estructura la iniciativa ciudadana. Los ECD son un enfoque intelectual que se articula de manera natural con el concepto de respuesta social. Proceder de forma sistemática sobre los corpus hace posible la comprensión de los discursos de respuesta social, dando cuenta de sus capacidades expresivas y de sus significados, vinculados a sus contextos sociohistóricos.

Además de los aportes teórico-epistémicos de los ECD, resulta de gran importancia enfatizar en el propósito ético político que propende por la generación de alternativas que contrarresten las formas de dominación del discurso masivo. De acuerdo con Van Dijk, las perspectivas críticas del discurso están para "solidarizarse con aquellos que han sufrido de dominación discursiva" (2004, p. 8). Lo que pone en sintonía el presente estudio con los horizontes éticos de los ECD.

Cuando se focaliza sobre actores invisibilizados se quiere escuchar las otras versiones de mundos posibles. Es una apuesta por poner lenguajes comunes con otros reconocibles, lo que se convierte en el primer paso del diálogo. El concepto de respuesta social parte del reconocimiento de las facultades de los grupos sociales para manifestarse frente a lo que los afecta.

Las formas de manifestación evidencian las capacidades expresivas de los grupos sociales que materializan, en un soporte tecnológico, sus puntos de vista y con ello exponen nuevos horizontes de comprensión que respondan a la complejidad de la realidad social. Así, las respuestas sociales son posibilidad frente a un problema de la comunicación contemporánea: las maneras de participación para la creación de discursos masivos que contengan visiones plurales y voces múltiples. En otras palabras, el acontecimiento aquí problematizado pone en evidencia el carácter excluyente del discurso mediático colombiano.

La fuerza sociocomunicativa de la respuesta social radica en su carácter múltiple. La multitud "brinda la posibilidad de que, sin dejar de ser diferentes, descubramos lo común que nos permite comunicarnos y actuar juntos. La multitud también puede ser concebida como una red abierta y expansiva" (Negri y Hardt, 2004, p. 18). \#Noen3caínes es un buen ejemplo de multitud. Son un conjunto de participantes con identidades diferentes que actuaron de manera organizada y en red.

Los participantes de la iniciativa tienen la posibilidad de cuestionar la coherencia de las empresas anunciantes por la identificación entre consumidor/marca. Este vínculo garantiza que sea de interés para las empresas anunciantes mantener una coherencia de imagen frente a sus potenciales compradores. El vínculo mercantil genera la toma de posición de parte de los anunciantes. El interés principal de los anunciantes no radica en distanciarse de discursos televisivos violentos. Más bien, se centra en crear o mantener el vínculo de identificación entre sus productos y los potenciales consumidores que les solicitaban coherencia.

El actor social "Movimiento cívico" plantea acciones con propósitos de circulación desde una esfera pública inmaterial como internet. El llamado de coherencia a las marcas es un acto que se construye públicamente desde redes digitales, lo que garantiza la toma de posición de los anunciantes. En esta nueva esfera pública "se matiza la centralidad del espacio público urbano de interacción cara a cara, así como la llamada esfera pública, y se promueve una nueva provista por una inmaterialidad de las redes electrónicas" (Rueda, 2008, p. 14). La eficacia de las acciones discursivas de \#Noen3caínes para transformar el escenario sociopolítico consistió en agrupar en una esfera inmaterial (como Twitter y Facebook) a una multiplicidad de personas con un descontento común por una propuesta televisiva. 


\section{RECONOCIMIENTOS}

Este documento forma parte de la tesis titulada: "Discursos de respuesta social frente a la teleserie Tres Caínes", para optar por el título de Magíster en Comunicación y Medios de la Universidad Nacional de Colombia. La directora de la tesis es la Dra. Neyla Pardo. Este documento constituye uno de los compromisos contractuales en el marco de la convocatoria Colciencias 645 de 2014 que financia esta tesis de investigación.

\section{REFERENCIAS BIBLIOGRÁFICAS}

Autoridad Nacional de Televisión (ANTV) (junio de 2013). La responsabilidad de los medios de comunicación frente a la memoria histórica y las víctimas del conflicto. Panel Medios y Redes Sociales, Dos Puntos de Vista. [Archivo de video]. Recuperado en marzo de 2016 de: https://www.YouTube. $\mathrm{com} /$ watch? $\mathrm{v}=\mathrm{G} 941 \mathrm{~J} 8 \mathrm{HCErM}$

Ayala O., G. (19 de marzo de 2013). Tres Caínes, de $\mathrm{RCN}$, pierde anunciantes. La otra tribuna. Recuperado de: http://laotratribuna1.blogspot.com. co/2013/03/tres-caines-de-rcn-pierde-anunciantes.html

Berger, P. y Luckmann, T. (2003). La construcción social de la realidad. Buenos Aires: Amorrortu Editores. Recuperado de: https://zoonpolitikonmx.files. wordpress.com/2014/09/la-construccic3b3n-social-de-la-realidad-berger-luckmann.pdf

Braga, J.L. (2006). A sociedade enfrenta suamidia: dispositivos sociais de crítica midiática. Sao Paulo: Pauluscomunicação.

Castaño M., G. (2013). La feria de los estereotipos. A/ma Máter. Recuperado de: http://almamater.udea. edu.co/periodico/sc-ana619-02.htm

Comisión Nacional de Reparación y Reconciliación (CNRR) (2013) ¡Basta ya! Colombia: memorias de guerra y dignidad. Bogotá: Centro Nacional de Memoria Histórica, Departamento para la Prosperidad Social (DPS). Recuperado de: http://www.centrodememoriahistorica.gov.co/descargas/informes2013/
bastaYa/bastaya-colombia-memorias-de-guerra-y-dignidad-2015.pdf

Consejo Académico de la Universidad de Antioquia (8 de marzo del 2013). Pronunciamiento: programa "Tres Caínes" y su alusión a la UdeA. Medellín: Universidad de Antioquia. Recuperado en noviembre de 2015 de: http://upublicaresiste.blogspot.com. co/2013/03/pronunciamiento-programa-tres-caines-y.html

Corporación Nuevo Arco Iris (21 de marzo de 2013). La batalla contra los Tres Caínes. Recuperado de: http://www.arcoiris.com.co/2013/03/ la-batalla-contra-los-tres-caines/

Cuartas, G. (2013). Carta abierta contra la serie Los Tres Caínes. Kienyke.com. Recuperado en noviembre de 2015 de: http://www.kienyke.com/noticias/ la-carta-de-gloria-cuartas/

De Miguel de Beriain, I. (2013). Recuperando el control sobre la economía: el consumo como herramienta de poder. Revista Dilemata, 5(13), 1-32. Barcelona: Editorial Board. Recuperado de: https://dialnet.unirioja.es/servlet/articulo?codigo $=4494890$

Diócesis de Quibdó (2013). Comunicado de la Diócesis de Quibdó. Los "Tres Caínes" en Bojayá. Quibdó. Recuperado en noviembre de 2015 de: http:// bojayaunadecada.org/2013/06/29/la-diocesis-dequibdo-se-pronuncia-sobre-tergiversaciones-de-laserie-de-tv-los-tres-caines/

Ortiz F., J.D. (16 de marzo de 2013). Manifestación ciudadana hace que Auteco retire la pauta en Tres Caínes. Elcolombiano.com. Recuperado de: http:// www.elcolombiano.com/tres_caines_auteco_retira_su_pauta_por_presiones_en_manifestaciones_ ciudadanas-AEEC_233726

García, C. y Cartagena, A. (junio de 2013). Narconovelas-Movimiento ciudadano \#Noen3caínes. [Archivo de video]. Recuperado en marzo de 2016 de: https://www.YouTube.com/watch?v=YAFW9qDxJlc

García M., M. (2013). La prohibición de la censura en la era digital. Revista Teoría y Realidad Constitucional, 31, 237-276. Madrid: UNED. Recuperado de: http://e-spacio.uned.es/fez/eserv. php?pid=bibliuned:TeoriayRealidadConstitucional-2013-31-6030\&dsID=Documento.pdf 
Guerra, C. (8 de abril de 2013). "Capítulo 1: El Salado". Periódico El Tiempo. Recuperado de: http://www. eltiempo.com/archivo/documento/CMS-12731830

Kress, G. (2000). Multimodality. En: B. Cope y M. Kalantzis (Eds.). Multiliteracies: Learning and the desing of social futures (pp. 182-202). Londres: Routledge.

Lakoff, G. y Johnson, M. (2004). Metáforas de la vida cotidiana. Madrid: Teorema. Recuperado de: https://linguisticaunlp.files.wordpress.com/2012/11/ lakoff-y-johnson.pdf

Lazzarato, M. (2003). Lucha, acontecimiento, media. Recuperado de: http://www.republicart.net/disc/ representations/lazzarato01_es.pdf

Lazzarato, M (2006). Por una política menor. Acontecimiento y política en las sociedades de control. Madrid: Traficantes de Sueños. Recuperado de: http:// www.museoreinasofia.es/sites/default/files/actividades/porunapoliticamenor.pdf

Lazzarato, M. (2007). La filosofía de la diferencia y el pensamiento menor. Bogotá: Universidad Central, IESCO.

López, C. (2010). Y refundaron la patria. De cómo mafiosos y políticos reconfiguraron el Estado colombiano. Bogotá: Random House Mondadori. Recuperado de: http://aprendeenlinea.udea.edu.co/revistas/index.php/folios/article/view/12771/11700

López H., A. (2001). La selección de documentos audiovisuales. Revista Documentación de las Ciencias de la Información, 24, 127-149. Recuperado de: http://revistas.ucm.es/index.php/DCIN/article/ viewFile/DCIN0101110127A/19517

Martín R., L. y Van Dijk, T. (1998). Había un problema y se ha solucionado. La legitimación de la expulsión de inmigrantes en el discurso parlamentario español. En: L. Martín y R. Whittaker. Poder-decir o el poder de los discursos (pp. 1-71). Madrid: Arrecife. Recuperado de: https://www.academia. edu/541657/_Hab\%C3\%ADa_un_problema_y_ se_ha_solucionado._La_legitimaci\%C3\%B3n_de_ la_expulsi\%C3\%B3n_de_inmigrantes_ilegales_ en_el_discurso_parlamentario_espa $\% \mathrm{C} 3 \% \mathrm{~B} 1 \mathrm{ol}$

Meyer, M. (2003). Entre la teoría, el método y la política: la ubicación de los enfoques relacionados con el ACD. En: R. Wodack y M. Meyer (comp.). Métodos de análisis crítico de discurso (pp. 35-59). Barcelona: Gedisa. Recuperado en marzo de 2016 de:http://analisisdeprensa.cl/web/wp-content/ uploads/2015/04/Libro-Wodak-Metodos-de-Analisis-Critico-del-Discurso-Wodak-y-Meyer.pdf

Mortara, 1991. Manual de retórica. Madrid: Cátedra. Recuperado de: https://drive.google.com/folderview?id=0B-GPqM-CVAWSajRHQmJMZnkydWM\&usp=sharing

Naranjo, D. (2013). Noen3caínes. [Actualización de Facebook]. Recuperado en marzo de 2016 de: https://www.facebook.com/ Noen3caines-490599870999308/timeline

Negri, A. y Hardt, M. (2004). Multitud. Guerra y democracia en la era del imperio. Barcelona: Random House Mondadori.

Pardo, N. (2007). Cómo hacer un análisis crítico de discurso. Una perspectiva latinoamericana. Bogotá: Instituto de Estudios en Comunicación y Cultura (IECO), Universidad Nacional de Colombia.

Pardo A., N. (2011). Aproximación al estado del arte de los estudios críticos del discurso. En: J. Ruiz Celis. Aproximaciones interdisciplinares al estado de los estudios del discurso (pp. 19-50). Bogotá: Universidad Nacional de Colombia.

Pardo A., N. (2012). Discurso en la web, pobreza en YouTube. Bogotá: Instituto de Estudios en Comunicación y Cultura (IECO), Universidad Nacional de Colombia.

Quiñones, B. (2009). Violencia y ficción televisiva: el acontecimiento de los noventa: imaginarios de la representación mediática de la violencia colombiana, series de ficción televisiva de los noventa (1989-1999). Bogotá: Instituto de Estudios en Comunicación y Cultura (IECO), Universidad Nacional de Colombia.

Radio Santafé (marzo de 2013). Los "Tres Caínes" se queda sin pauta por su contenido. Recuperado de: http://www.radiosantafe.com/2013/03/20/los-trescaines-se-quedan-sin-pautas-por-su-contenido/

Rueda, R. (abril de 2008). Cibercultura: metáforas, prácticas sociales y colectivos en red. Revista Nómadas, 1(28), 8-20. Bogotá: Universidad Central. 
Recuperado de: http://www.scielo.org.co/pdf/ noma/n28/n28a2

Siglo Data MMI (22 de marzo de 2013). Los Tres Caínes y la pauta publicitaria. Recuperado de: http://colombia.mmi-e.com/blog/ los-tres-ca\%C3\%ADnes-y-la-pauta-publicitaria

Tercer Canal (marzo de 2013). Plantón No más Tres Caínes. [Archivo de video]. Recuperado en marzo de 2016 de: https://www.YouTube.com/ watch? $v=j \mathrm{~B}-\mathrm{a} 1 \mathrm{p} 3 \mathrm{Nql} 8$

Valencia, C. (8 de abril de 2013). "Capítulo uno: El Salado". El Tiempo. Recuperado de: http://www.eltiempo.com/archivo/documento/CMS-12731830

Van Dijk, T. (2001). El discurso como interacción en la sociedad. En: El discurso como interacción social. Estudios sobre el discurso II. Una introducción multidisciplinaria (pp. 19-66). Barcelona: Gedisa.
Van Dijk, T. (17 de febrero de 2004). Discurso y dominación. Lección inaugural de la Facultad de Ciencias Humanas. Bogotá: Universidad Nacional de Colombia. Recuperado de: http://www.discursos. org/oldarticles/Discurso\%20y\%20dominaci\%F3n. pdf

Vasilachis de Gialdino, I. (1992). Métodos cualitativos I. Los problemas teórico epistemológicos. Buenos Aires: Centro Editor de América Latina. Recuperado de: http://seminariodesafios.sociales.uba.ar/ files/2014/09/Vasilachis-I-at-al.-M\%C3\%A9todos-culitativos-I.pdf

Zélik, R. (2015). Paramilitarismo. Violencia y transformación social, política y económica en Colombia. Bogotá: Siglo del Hombre Editores, Fescol, Goethe Institut. Recuperado de: http://justiciaypazcolombia. com/IMG/pdf/paramilitarismo_en_colombia.pdf 